\title{
Restitution of visual function in patients with cerebral blindness
}

\author{
J. Z I H L A ND D. VON CRAMO N \\ From the Max-Planck-Institut für Psychiatrie, München, Germany
}

SUMMARY Patients with postchiasmatic visual field defects were trained at the border of their visual field. Using a psychophysical method, light-difference thresholds were determined repeatedly in this visual field area. Improvement in contrast sensitivity and increase in size of the visual field could be obtained by this training procedure. The improvement was confined to the trained visual field area and showed interocular transfer indicating its central nature. Although only contrast sensitivity was trained, the observed improvement was not limited to this visual function. Visual acuity, critical flicker fusion, and colour perception also showed an improvement suggesting an association of these functions. The improvement was restricted to the training period-no spontaneous recovery was observed between or after the periods of training. It is suggested that a lesion in the central visual system does not always result in a complete and permanent loss of function. The critical level of function that normally has to be reached for a sufficient neuronal sensitivity may be obtained by systematic visual stimulation in the area between the intact and blind parts of the visual field. This increase in neuronal sensitivity leads to an improvement in visual performance.

Lesions within the central visual pathways do not necessarily result in absolute and permanent visual field defects (Teuber, 1975). Perimetric "blind" or impaired visual field areas may fluctuate in sensitivity (Bender and Teuber, 1946). Recovery of visual function has been observed in patients with postchiasmatic lesions although return of vision is rarely complete (Bergmann, 1957; Symonds and Mackenzie, 1957). Reappearance takes place in a definite temporal order: sensation of light and motion, form perception, colour perception (Poppelreuter, 1917; Riddoch, 1917).

Bender and Teuber (1946) suggested that fluctuations in the extent and size of a cortical scotoma are correlated with the variation of neuronal sensitivity in the cortical area which is affected by the lesion. In the corresponding visual field partsthat is, at the border of the visual field-fluctuation and extinction of visual function can be observed. For these parts of the visual field a diurnal variation of light sensitivity was found (Zihl et al., 1977a). The transition between the intact parts of the visual field and the scotoma

Address for correspondence and reprint requests: J. Zihl, MaxPlanck-Institut für Psychiatrie, Kraepelinstrasse 10, 8000 München 40 Federal Republic of Germany.

Accepted 6 October 1978 may be abrupt or gradual (Körner and Teuber, 1973). Visual fields with sharp scotoma boundaries show only a slight recovery of function, whereas for visual fields with rather gradual borders of the defect some degree of recovery can be observed (Teuber, 1974; Zihl et al., 1977b).

The question arises whether the level of neuronal sensitivity can be modulated by systematic external stimulation in order to improve recovery of visual function. An increase in sensitivity in impaired or perimetrically "blind" parts of the visual field may result in the restitution of vision in these areas and thus in an enlargement of the visual field. Evidence for such an increase in sensitivity in impaired or scotomatous visual field parts has come from experiments with monkeys (Cowey and Weiskrantz, 1963; Cowey, 1967). Visual stimulation in the area between intact and blind parts of the visual field leads to a decrease of the scotoma. Observations in human subjects are in agreement with the effect of stimulation in monkeys. Stimulation of impaired visual field areas with cortically reduced visual functions increases sensitivity and visual field size, although fatigue may take place rapidly and result in an overall reduction of visual function (Pöppel et al., 1978).

The purpose of this paper is to present evidence 
that diminished visual function can be improved by systematic stimulation of the impaired areas of the visual field. Since light sensation reappears first in blind areas, this visual function was trained in order to improve visual performance. To demonstrate the central nature of the increase in contrast sensitivity obtained by the training procedure, interocular transfer was tested. We also investigated whether improvement takes place only in a defined area of the visual field (according to the central representation of the retina). In addition, periods without training were included to show that the increase in sensitivity depends on the training session and is not the result of spontaneous recovery.

\section{Methods}

\section{VISUAL FIELD EXAMINATION}

The visual fields were tested by dynamic and static perimetry using the Tübinger perimeter (Sloan, 1971; Aulhorn and Harms, 1972). The patients fixated a red spot of light $(10$ or $30 \mathrm{~min}$ visual angle in diameter) at a distance of $330 \mathrm{~mm}$. Background luminance was $3.2 \mathrm{~cd} / \mathrm{m}^{2}$. Head position was held stable by a chin rest; eye position was controlled through a telescope.

For dynamic perimetry, the target (diameter $116 \mathrm{~min}$ visual angle; luminance $32 \mathrm{~cd} / \mathrm{m}^{2}$ ) was moved with a constant velocity of about $2 \% / \mathrm{s}$ from the periphery towards the centre of the visual field. The patient had to push a button whenever he detected the target. The border of the visual field was determined for 16 meridians, and the sequence of measurements along the different meridians was randomised. The visual fields were tested under monocular and binocular conditions.

Static perimetry was performed by measuring binocular increment threshold using the method of limits. Fixation point and background luminance were the same as for dynamic perimetry. Target diameter was $69 \mathrm{~min}$ visual angle; presentation time $500 \mathrm{~ms}$. Target luminance was chosen well above or below threshold level and was then decreased or increased in steps of $0.1 \mathrm{log}$ units. When the patient detected three targets consecutively, the luminance of the first of these was defined as the threshold for the ascending method. For the descending series of threshold measurements, the luminance of the last seen target was defined as the threshold-that is, when after this target was seen, three consecutive targets were not detected by the patient.

In addition critical flicker frequency (CFF), visual acuity, and colour perception were tested for both eyes. For measurement of CFF the target had a diameter of $116 \mathrm{~min}$ visual angle; target luminance was $32 \mathrm{~cd} / \mathrm{m}^{2}$. The patient pushed a button when he could detect flickering of the target (for ascending series) or when flicker was no longer detectable (for descending series). For testing visual acuity, the patient's task was to indicate whether he saw a circular or a diamondshaped target. Luminance of the targets was $32 \mathrm{~cd} / \mathrm{m}^{2}$ and they were presented for one second. Order of presentation was randomised. Errorless performance was chosen as the criterion of acuity. Critical flicker frequency and visual acuity were determined with the Tübinger perimeter. For testing binocular colour perception, the FarnsworthMunsell 100-hue test was used (Farnsworth, 1943).

TRAINING PROCEDURE

Visual training was performed with the Tübinger perimeter. The method of limits was used to improve sensitivity to light stimuli. Monocular and binocular contrast thresholds were determined several times at a constant eccentricity in the area between visual field and scotoma. The interstimulus interval between presentations was about three seconds; time between measurements was in the range of 10-30 seconds in order to prevent fatigue (Singer et al., 1977). As a control of the patient's detection strategy, blanks were interspersed among targets. Usually, 15-20 contrast thresholds were determined in one session with a break of about five minutes after five measurements.

The patient was instructed to fixate a red spot of light in the centre of the homogeneously illuminated sphere (background luminance $3.2 \mathrm{~cd} / \mathrm{m}^{2}$ ), and to direct his attention to the area where training was performed. Within training sessions, the patients were reinforced for their fixation and their attention. They were not informed about an increase or decrease in sensitivity until they experienced a progress in vision in their everyday life outside the laboratory. Training sessions were performed daily at the same time for each patient; usually one session took an hour.

\section{CONTROL OF TRAINING EFFECTS}

Visual fields were mapped before and after training sessions using dynamic perimetry. In addition lightdifference threshold was measured along the meridian selected for training before and after training; the difference was taken as change in sensitivity. For determination of the retinotopic dependence of improvement, increment threshold was determined at various points surrounding the position of training. To test interocular transfer, training was performed monocularly. Transfer was 
tested by comparing contrast threshold in the corresponding visual field area of the covered eye before and after training. In order to control "spontaneous" recovery visual field size and visual sensitivity between the end of the foregoing session (or period) and the beginning of the next session (or period) were compared. In addition, visual acuity, critical flicker fusion or colour perception were tested before and after training.

\section{Subjects}

Training was performed in 12 patients who had suffered visual field defects because of postchiasmatic lesions. The clinical details are summarised in Table 1. The lesions had been verified by computer tomography or cerebral angiography or both (Zihl et al., 1978). All patients except cases 6 and 10 suffered from cerebrovascular diseases. The time between the first evidence of the visual field defect and start of training varied from one month (case 6) to nearly six years (case 8). No remarkable spontaneous recovery of visual function was observed in the majority of cases. In case 6 light and movement perception returned in the periphery of the right visual half-field soon after the operation. In case 10 perception of light and movement and some kind of colour and form perception recovered in the periphery of the visual field, whereas the central scotoma remained unchanged.

All patients showed good performance in fixation. No obvious neurological defects (that is, for oculomotor, motor, and speech behaviour or attention and memory) were found when training was started. The main problem for these patients was the failure to avoid obstacles at the side of their scotoma and the restriction of their visual orienta- tion. Some patients, however, exhibited residual vision (Pöppel et al., 1973). Sometimes they "felt" objects appearing within their blind half-field. Furthermore, all patients with the boundary of the scotoma near the fovea (along the horizontal meridian) had problems in reading because words appeared "cut off" on the right or left side. All patients were highly motivated although they were informed that this visual training was only an attempt to improve their visual performance.

\section{Results}

In the first training session, the repeated measurement of light-difference threshold resulted in a decrease in sensitivity. In most of the patients the increase in sensitivity was obtained after three to five sessions (Fig. 1A). In one patient (case 5), improvement in contrast sensitivity was first observed during the eighth session. This decrease in sensitivity in the first sessions may be the result of fatigue, even though longlasting breaks were introduced between measurements. After this first phase of training a rather remarkable improvement was obtained within one session (Fig. 1B). The increase in contrast sensitivity was alway greater for the periphery of the visual field (up to $0.5 \mathrm{log}$ units) than for the region near the fovea $(0.2 \log$ units; see Fig. $1 \mathrm{~B}$ and Table 2$)$. The $\overrightarrow{0}$ improvement in contrast sensitivity showed almos 0 total interocular transfer (Fig. 2). Increase in light sensitivity was not restricted to the trained visual field position. As can be seen in Fig. 2, improvement extended over an area of $8^{\circ}$ when training was performed at $14^{\circ}$ eccentricity along the $45^{\circ}$ meridian. The area within which improvement was also found increased with increasing eccentricity. Figure 3 shows this effect. When

Table 1 List of patients with clinical details

\begin{tabular}{|c|c|c|c|c|c|}
\hline Case & $\operatorname{Sex}$ & $\begin{array}{l}\text { Age } \\
(y r)\end{array}$ & Diagnosis & Visual field defect & $\begin{array}{l}\text { Time since } \\
\text { lesion* }\end{array}$ \\
\hline 1 & $\mathbf{M}$ & 42 & Occlusion of the left post. cerebral artery with infarction & Right hemianopia & $0 / 11$ \\
\hline 2 & $\mathbf{M}$ & 64 & Occlusion of the left calcarine artery with infarction & Anopia of right upper quadrant & $0 / 6$ \\
\hline 3 & $\mathbf{F}$ & 33 & Occlusion of the right post. cerebral artery with infarction & Left hemianopia & $0 / 5$ \\
\hline 4 & $\mathbf{F}$ & 35 & $\begin{array}{l}\text { Partial occlusion of the left middle cerebral post. cerebral } \\
\text { arteries with infarction }\end{array}$ & Right hemianopia & $3 / 1$ \\
\hline 5 & $\mathbf{M}$ & 57 & Bilateral occipital haemorrhage & $\begin{array}{l}\text { Right hemianopia. Anopia of } \\
\text { left lower quadrant }\end{array}$ & $4 / 9$ \\
\hline 6 & $\mathbf{F}$ & 61 & Tumour in the left occipital lobe (operated) & Paracentral right sided scotoma & $0 / 1$ \\
\hline 7 & $\mathbf{M}$ & 19 & Right temporobasal epidural haematoma (operated) & Left hemianopia & $0 / 2$ \\
\hline 8 & $\mathbf{M}$ & 52 & Embolic occlusion of the right middle cerebral artery & Left hemianopia & $5 / 11$ \\
\hline 9 & $\mathbf{M}$ & 31 & $\begin{array}{l}\text { Papilloma of the choroidal plexus of the left posterior } \\
\text { horn (operated) }\end{array}$ & Right hemianopia & $0 / 7$ \\
\hline 10 & $\mathbf{F}$ & 33 & Cerebral hypoxia & Central scotoma & $0 / 6$ \\
\hline 11 & $\mathbf{F}$ & 45 & Intracerebral haemorrhage of the putamen-claustrum type & Anopia of left lower quadrant & $0 / 1$ \\
\hline 12 & $\mathbf{M}$ & 48 & $\begin{array}{l}\text { Bilateral partial occlusion of the middle cerebral artery } \\
\text { and partial occlusion of the left post. cerebral artery } \\
\text { with infarction }\end{array}$ & Incomplete right hemianopia & $0 / 2$ \\
\hline
\end{tabular}

*Time (in years/months) from evidence of visual field defect to beginning of training. 

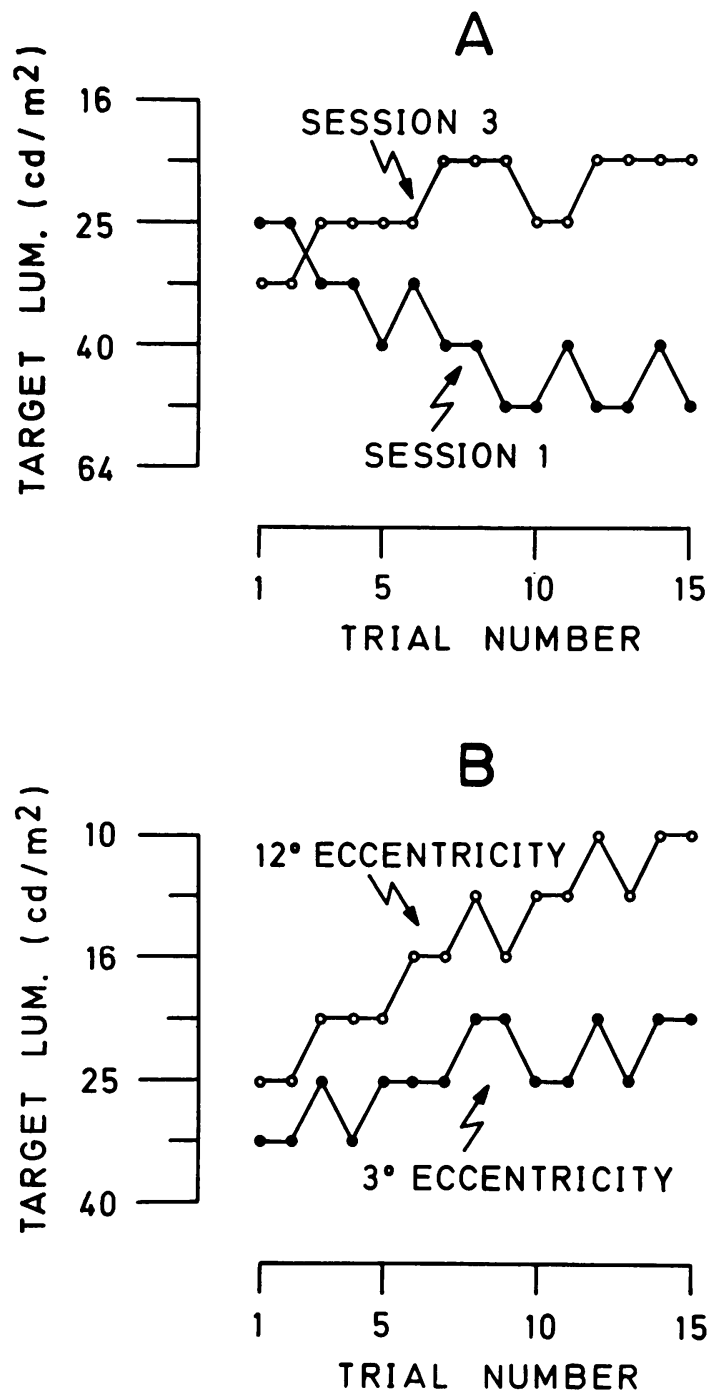

Fig. 1 Course of light-difference threshold during one training session consisting of 15 measurements (case 9). Increase in contrast sensitivity was obtained first time in the third session $\left(A, 3^{\circ}\right.$ eccentricity $/ 0^{\circ}$ merid an). The improvement is greater for the periphery of the visual field $\left(0.4 \log\right.$ units at $\left.12^{\circ}\right)$ than for the foveal region $\left(B, 0.2 \log\right.$ units at $\left.3^{\circ}\right)$.

training was performed at $8^{\circ}$ eccentricity along the horizontal meridian, the area of improvement extended over approximately 10 degrees (Fig. 3A), whereas for a training position near the fovea $\left(1^{\circ}\right)$ an increase in sensitivity was obtained for this position only (Fig. 3B). Interocular transfer and retinotopic dependence of the training effect in the course of a training period are demon-
Table 2 Maximal increase in contrast sensitivity for various eccentricities (mean of five patients)

\begin{tabular}{lll}
\hline $\begin{array}{l}\text { Eccentricity } \\
\text { (degrees) }\end{array}$ & $\begin{array}{l}\text { Maximal increase } \\
\text { (log units) }\end{array}$ & $\begin{array}{l}\text { Range } \\
\text { (log units) }\end{array}$ \\
\hline 1 & 0.10 & \\
2 & 0.14 & $0.10-0.20$ \\
3 & 0.18 & $0.10-0.30$ \\
4 & 0.24 & $0.20-0.30$ \\
5 & 0.26 & $0.20-0.30$ \\
8 & 0.32 & $0.20-0.40$ \\
10 & 0.32 & $0.20-0.40$ \\
15 & 0.40 & $0.30-0.50$ \\
18 & 0.40 & $0.30-0.50$ \\
20 & 0.41 & $0.30-0.50$ \\
24 & 0.44 & $0.30-0.60$ \\
\hline
\end{tabular}

strated in Fig. 4. This patient (case 10) showed a central scotoma (Fig. 4A, hatched area). Training was performed in the visual field of the left eye, while the right eye was covered by an occluder. With one eye closed the patient was able to keep fixation stable using a black circle as a "fixation" point for the blind spot. During the first period of training, the threshold was measured along the horizontal meridian in the right visual half-field. As can be seen in Fig. 4B, the training effect was not limited to the trained area but was obtained within the whole "blind" central region (Fig. 4B, 29.10.76). After this overall effect of visual stimulation any further increase in sensitivity was limited to the area actually trained. After approximately two months of training, no more visual field defect could be detected and normal contrast sensitivity was obtained within the previous central scotoma (Fig. 4A). Increase in contrast sensitivity showed complete transfer to the occluded right eye. Static perimetry demonstrated identical sensitivity profiles for the visual field of both eyes (Fig. 4B).

The increase in visual field size obtained by training of contrast sensitivity varied from patient to patient (see Table 3 ). In some of the patients (cases $1,5,6,7$, and 10) visual function improved in the area between visual field and scotoma after a few trials (12-40 thresholds measurements). In other patients, up to 260 trials were necessary to increase visual field size by one degree (cases 4 , 8,11 , and 12). In the latter patients, the slope of the light-difference threshold between visual field and scotoma was steep, whereas in the other cases the slope was rather gradual.

Increase in visual field size and contrast sensitivity for four patients is shown in Figs. 5 and 6. In the two patients shown in Fig. 5 training had a dramatic effect on restitution of visual field. The visual field of the first patient (Fig. 5A, case 5) was extremely reduced and behaviourally he was blind. 

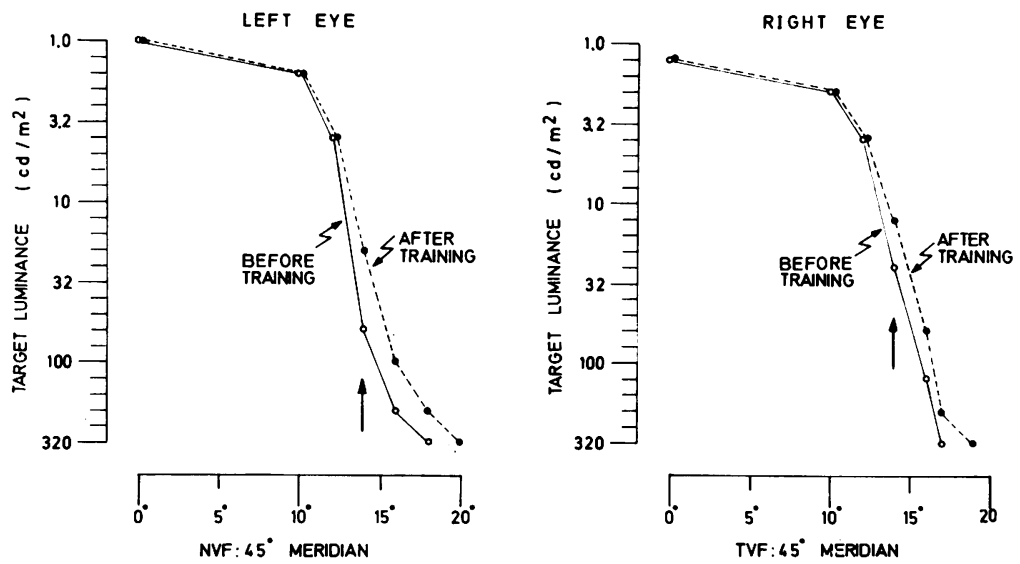

Fig. 2 Interocular transfer of the training effect. Training was performed in the nasal visual field of the left eye $\left(45^{\circ}\right.$ meridian; $14^{\circ}$ eccentricity, indicated by arrow), while the right eye was occluded (case 1). The increase in contrast sensitivity was also observed after training in the corresponding region of the temporal visual field of the right eye (arrow) and shows the central nature of the improvement by training.

A

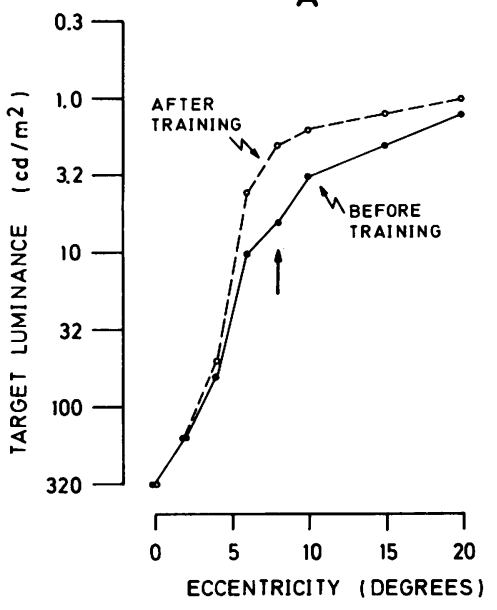

B

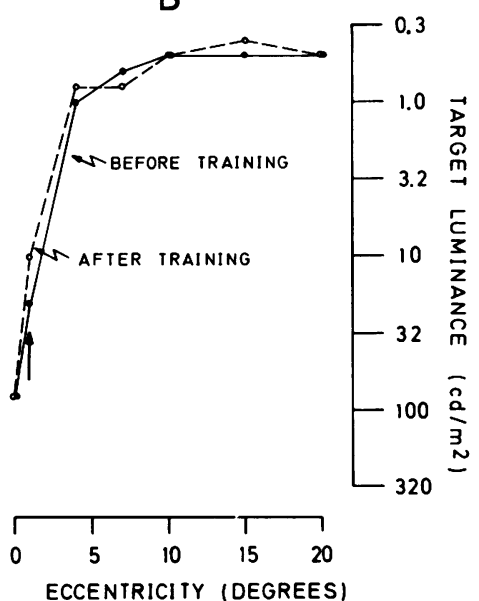

Fig. 3 Light-difference threshold before and after one training session (case 10). The increase in visual sensitivity and the area within which improvement was also found, were greater for $8^{\circ}$ eccentricity $\left(0^{\circ}\right.$ meridian, $\left.A\right)$ than for $1^{\circ}$ eccentricity $(B)$.
He used acoustic and tactile cues to find his way around. Training was performed along the whole visual field border. At the end of the training period the left upper quadrant was restituted. The patient is now able to walk using visual cues. He can perceive colour and form, and is able to read a newspaper. The second patient (Fig. 5B, case 6) suffered from a right paracentral scotoma. As with the first patient, training was performed along the whole visual field boundary. After 30 training sessions, the right visual half-field showed normal contrast sensitivity except for a relative scotoma at $8^{\circ}$ eccentricity along the horizontal meridian. Subjectively this patient exhibited normal visual perception. In another patient (Fig. 6A, case 8), training did not produce such a marked increase in visual field size. Although as many trials were conducted as for the two patients reported above, the increase in visual field size along the horizontal meridian (where training was performed) was only $2^{\circ}$. This rather slight enlargement, however, was sufficient to allow normal reading. In the last patient shown in Fig. 6B (case 9), training produced an increase of $15^{\circ}$, although the boundary of the scotoma before training was at $4^{\circ}$ eccentricity (horizontal meridian) for both patients. The slope, however, was rather gradual for case 9 (cf. static perimetry for both cases at the right side of Fig. 6). Training was performed along the horizontal meridian and restitution of the visual field was obtained mainly along this meridian. The enlargement of the visual field in the upper and lower quadrant (about $2^{\circ}$ ) is due to the overall effect in the first sessions as stated above.

From the data reported it is not yet clear whether the improvement in contrast sensitivity is spontaneous or the result of the systematic exter- 
A

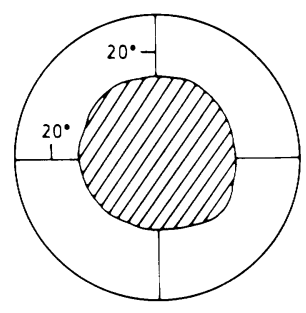

B
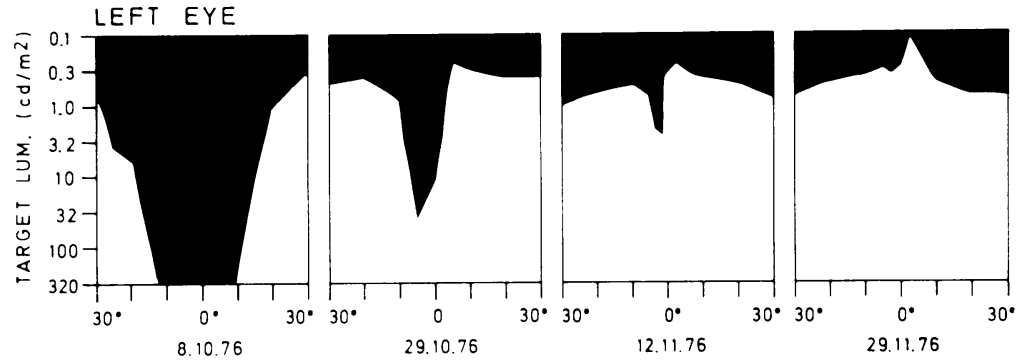

RIGHT EYE
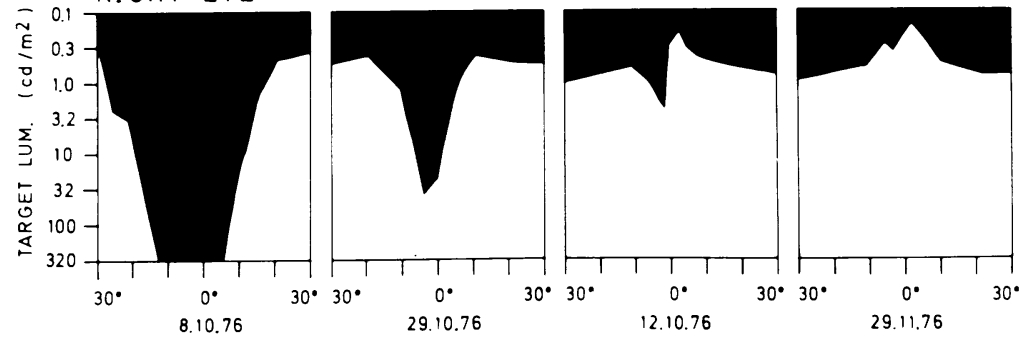

Fig. 4 Time course of restitution of contrast sensitivity in a case of central scotoma (case 10). The blind central part of the binocular visual field $(A$, hatched area) shows normal contrast sensitivity at the end of the training period (cf. contrast thresholds shown top right). Training was performed only in the visual field of the left eye; the right eye was always occluded during the training sessions. The scotomatous region (black area in $B$ ) decreases in both visual fields in a similar way.
Table 3 Number of trials, increase in visual field size, and trials per degree restituted visual field

\begin{tabular}{rlcrc}
\hline Case & $\begin{array}{l}\text { Trial } \\
\text { number }\end{array}$ & $\begin{array}{l}\text { Increase in visual } \\
\text { field size } \\
\text { (degrees) }\end{array}$ & Trials/degree \\
\hline 1 & 380 & $10-24$ & 14 & 27 \\
2 & 195 & $7-10$ & 3 & 65 \\
3 & 220 & $2-7$ & 5 & 44 \\
4 & 260 & $4-5$ & 1 & $260^{*}$ \\
5 & 315 & $25-50$ & 25 & 12 \\
6 & 535 & $1-28$ & 27 & 20 \\
7 & 180 & $5-12$ & 7 & 26 \\
8 & 530 & $2-4$ & 2 & $265^{*}$ \\
9 & 560 & $3-17$ & 14 & 40 \\
10 & 320 & $10-10$ & 20 & 16 \\
11 & 360 & $1-5$ & 4 & $90^{*}$ \\
12 & 210 & $8-9$ & 1 & $210^{*}$ \\
\hline
\end{tabular}

*Patients with an abrupt transition between intact and blind parts of their visual field.

nal stimulation. To decide this question. contrast thresholds between daily sessions and between periods without visual training were compared. Results are shown in Fig. 7 for two patients (case
6 and case 9). Improvement in contrast sensitivity was limited to the training session (Fig. 7A and B) and to the training period (Fig. 7C and D). Intervals without training did not show any influence on contrast sensitivity in the area between intact and blind parts of the visual field. No obvious increase or decrease in visual field size was observed, indicating that restitution of visual function depends strongly on systematic visual stimulation along the boundary of the visual field. Furthermore, improvement obtained by visual training did not disappear during periods without training or after training. Control measurements six months after the end of training support the view of lasting restitution of visual function.

In all patients described, restitution of contrast sensitivity was followed by return of resolution of form, critical flicker fusion, and colour perception. The increase in various visual functions was not limited to the restored visual field area-these visual functions also showed improvement in the 


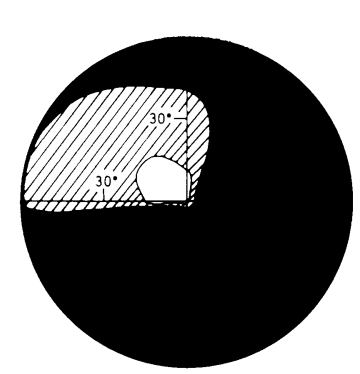

$A$

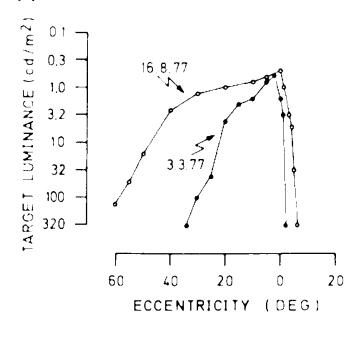

B
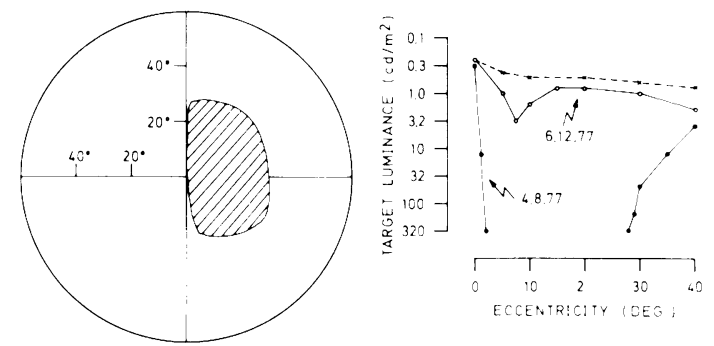

Fig. 5 Binocular visual field (left) and profile of contrast sensitivity (right) before and after the training period in a patient with a bilateral occipital lesion ( $A$, case 5$)$ and in a patient with a left occipital lesion ( $B$, case 6$)$. Hatched area indicates enlargement of the visual field obtained by training. Contrast sensitivity is shown for the horizontal axis of the visual field. The broken line in B indicates contrast sensitivity for the $0^{\circ}$ merid:an left visual half-field.

unimpaired visual field regions, for example, in the foveal region (Table 4). Only in the patient with the central scotoma (case 10) did spatial resolution remain unchanged in spite of the intact visual field for contrast sensitivity after the training.

Colour perception was preserved in most of the patients. In some cases, however, colour discrimination was also affected by the cerebral lesion. These patients (cases 5, 6, 7, and 8) showed a low discrimination profile without any specific deficit. After the training period the discrimination profile of these patients was normal according to the profile obtained from subjects with normal vision (Farnsworth, 1943). For cases 5 and 10, the mean of error scores was markedly reduced after training (from nine errors to four errors).

\section{Discussion}

Our purpose in this study was to explore the possibility of restitution of vision in patients with lesions of the geniculostriatal visual system. The results indicate that visual field size in these
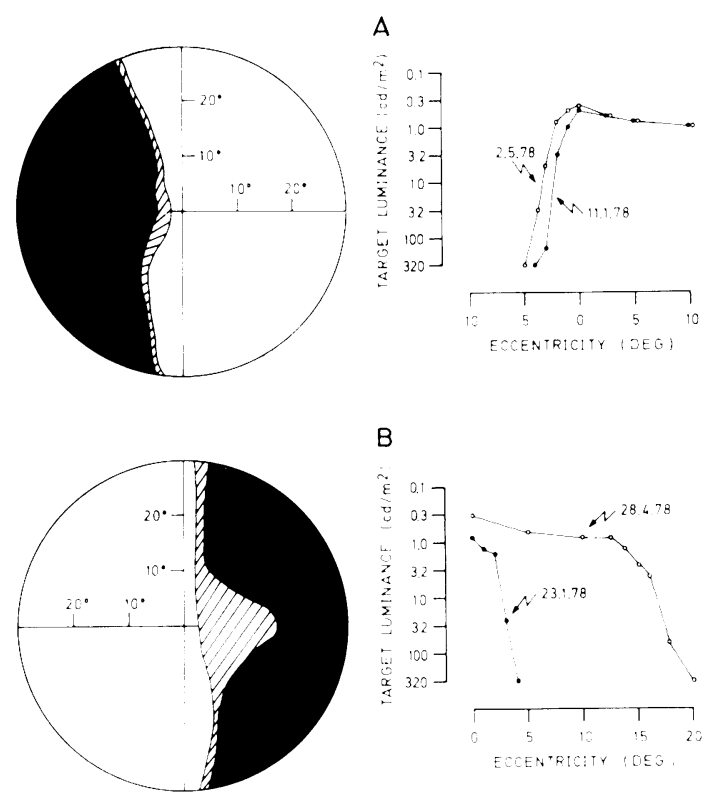

Fig. 6 Binocular visual field (left) and contrast sensitivity profile (right, horizontal meridians) in two patients with cerebral infarction $(A$, case $8 ; B$, case 9) before and after the training period.

patients can be increased by systematic external stimulation. Lowering light-difference threshold in the area of diminished sensitivity between the intact and the blind parts of the visual field leads to an increase in contrast sensitivity and to an enlargement of the visual field in the trained region. The increase in visual field size had a rather dramatic effect on the visual behaviour in most of the patients. Since other visual functions - for example, colour and form perception-also returned in the restituted visual field area, the visual capacities were sufficient for normal vision (visual orientation; form discrimination, reading). This improvement in vision is strongly dependent on the training period and is thus not the result of spontaneous recovery. The interocular transfer of the increase in contrast sensitivity indicates that the training effect occurs at a central site in the visual system.

The observation that loss or impairment of visual function can be diminished with practice is in agreement with observations in primates. After a partial lesion of the striate cortex in monkeys recovery of the corresponding scotoma was obtained by systematic external stimulation in the area between the intact and blind parts of the visual field. This improvement in sensitivity was not the result of spontaneous recovery since post- 

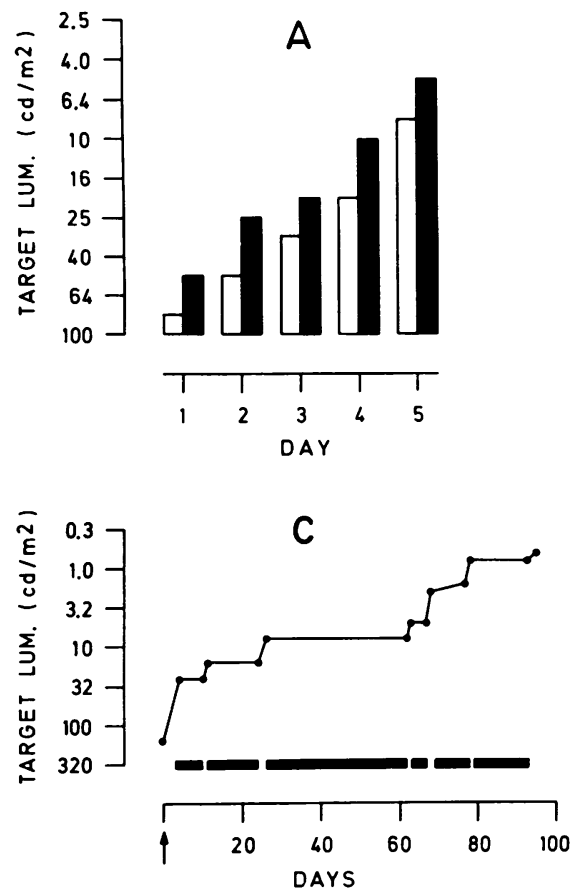
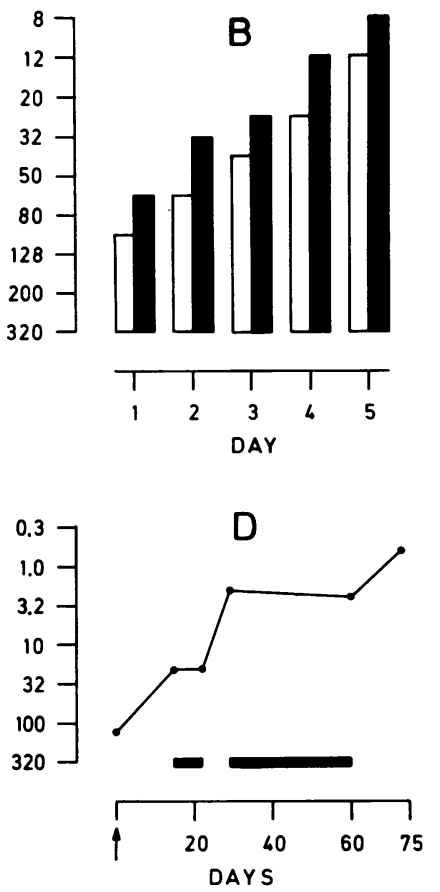

Fig. 7 Light-difference threshold before and after $a$ single training session $(A, B)$ and course of contrast sensitivity during periods of training and intervals without training $(C, D)$. Increase in contrast sensitivity is limited to the training session; the threshold after each session (black bars) is the same as before the next training session on the next day (white bars). In $A$, threshold was measured along the $0^{\circ}$ meridian at $2^{\circ}$ eccentricity (case 6 ), in $B$ at $10^{\circ}$ eccentricity along the same meridian. In intervals without training $(C, D$ dark lnes at the bottom) no increase in contrast sensitivity was observed ( $C$, case $6 ; D$, case 9$)$. Meridian and eccentricity same as in $A$ and $B$.
Table 4 Spatial and temporal resolution before and after training. Values for the fovea

\begin{tabular}{|c|c|c|c|c|c|c|}
\hline \multirow[t]{2}{*}{ Case } & \multicolumn{3}{|c|}{ Spatial resolution } & \multicolumn{3}{|c|}{ Temporal resolution } \\
\hline & $\begin{array}{l}\text { Before } \\
\text { (min } \\
\text { arc) }\end{array}$ & $\begin{array}{l}\text { After } \\
(\min \\
\text { arc })\end{array}$ & $\begin{array}{l}\text { Increase* } \\
(\%)\end{array}$ & $\begin{array}{l}\text { Before } \\
(\mathrm{Hz})\end{array}$ & $\begin{array}{l}\text { After } \\
(\mathrm{Hz})\end{array}$ & $\begin{array}{l}\text { Increase } \\
(\%)\end{array}$ \\
\hline $1+$ & 12 & 7 & 37 & 31 & 34 & 14.7 \\
\hline 2 & 12 & 12 & - & 30 & 31 & 3.2 \\
\hline $3+$ & 7 & 7 & - & 28 & 32 & 12.5 \\
\hline $4+$ & 12 & 12 & - & 29 & 31 & 6.5 \\
\hline $5+$ & 18 & 7 & 60 & 24 & 30 & 20.0 \\
\hline 6 & 12 & 7 & 37 & 31 & 36 & 13.9 \\
\hline $7_{+}^{+}$ & 12 & 7 & 37 & 26 & 35 & 25.7 \\
\hline $8_{+}^{+}$ & 7 & 7 & - & 30 & 34 & 11.7 \\
\hline $9+$ & 18 & 7 & 60 & 29 & 33 & 12.1 \\
\hline $10^{+}$ & - & $69 \S$ & & - & $35 \&$ & \\
\hline 11 & 18 & 7 & 60 & 26 & 30 & 10.3 \\
\hline 12 & 12 & 12 & - & 26 & 30 & 13.3 \\
\hline
\end{tabular}

${ }^{*}$ Increase in $\%$ of relative acuity.

†CFF after training taken as $100 \%$

†Corrected for hypermetropia or myopia.

§After visual field was intact for contrast sensitivity.

operative testing was performed two and a half years after removal of the cortical tissue. If a visual field defect is produced by a retinal lesion, no recovery either spontaneously or with practice was observed by Cowey (1967). This result correlates with the observed increase in visual field size in our patients using a similar psychophysical method of training.
The increase in visual field size is limited to the trained region and is not an overall effect of stimulation. The visual field region within which improvement was also found becomes larger towards the periphery of the visual field. The diameter of this region, however, remains approximately the same if corrected by the cortical magnification factor. The correspondence of the enlargement of the visual field with the known central representation of the visual field in primates (Daniel and Whitteridge, 1961; Rolls and Cowey, 1970) and the retinotopic dependence of the training effect indicate that the increase in visual field size depends on the primary visual cortex. For the prestriate areas of the monkey, a retinotopically organised representation of the visual field was no longer found (Zeki, 1971).

The neuronal mechanism underlying the obtained restitution of visual functions is not yet clear. Lashley (1938) has pointed out that restitution of function in the cerebral cortex depends strongly upon the preservation of some part of the system affected by the lesion. A critical amount of tissue must remain intact for the recovery of the diminished or depressed function. The transition zone between the intact visual field and the scotoma may be correlated with parts of intact tissue at the border of the lesion. It may be suggested, therefore, that the transition zone (ex- 
pressed in terms of the course of light-difference threshold) represents the functional level of still intact cortical neurones. Thus, a critical degree of functional level is necessary to mediate sensation in a partially damaged visual system. Diurnal variation in visual field and spontaneous recovery have been observed in patients with a rather gradual decrease of contrast sensitivity in this area (Zihl et al., 1977a,b). Furthermore, in patients with such a gradual transition a fairly good restitution was obtained by training, whereas in patients with an abrupt transition between the visual field and the scotoma, restitution was negligible.

Restitution or "reorganisation" of function may be understood in terms of the interaction of the remaining parts of the affected system (Lashley, 1938). This means that restricted lesions do not necessarily abolish the functional organisation of a neuronal network. Since even other visual functions reappeared in the restituted visual field area it may be assumed that the mode of perceptual processing was not affected by the lesion. In addition, the recovery of non-trained visual functions suggests an associative representation of these functions (Pöppel et al., 1978).

It is also an open question which factors modulate neuronal sensitivity and thus mediate the effect of training observed in our patients. One important factor could be selective attention which is known to modulate light-difference threshold in the visual field (Zihl et al., 1979). The improvement in sensitivity depends strongly on attentional processes. The relationship between light-difference threshold and attention is shown in Fig. 8. The diminution of contrast sensitivity is marked when the patient does not know where the target will appear and thus can not direct his attention to that area of the visual field. The neurophysiological mechanisms underlying the increase or decrease in sensitivity in relation to attention are not known. A modulation dependent on reticular activation might be envisaged, since reticular stimulation leads to facilitatory effects in geniculate and striatal neurones (Singer, 1973; Singer et al., 1976). It has been suggested that this effect may be caused by a shift of attention modulating the excitability of the neuronal substrate (Bartlett and Doty, 1974). Recently it has been shown that collicular pathways mediate the modulation of sensitivity in the visual field, probably by shifting visual attention (Singer et al., 1977). This is in line with electrophysiological observations in the superior colliculus of monkeys (Wurtz and Goldberg, 1972). Furthermore, other cerebral structures-for example, the parietal lobes-may be involved in the mechanism for directed attention (Lynch et al., 1977; Mountcastle, 1978). The relationship between the improvement of depressed visual function and attention indicates that the

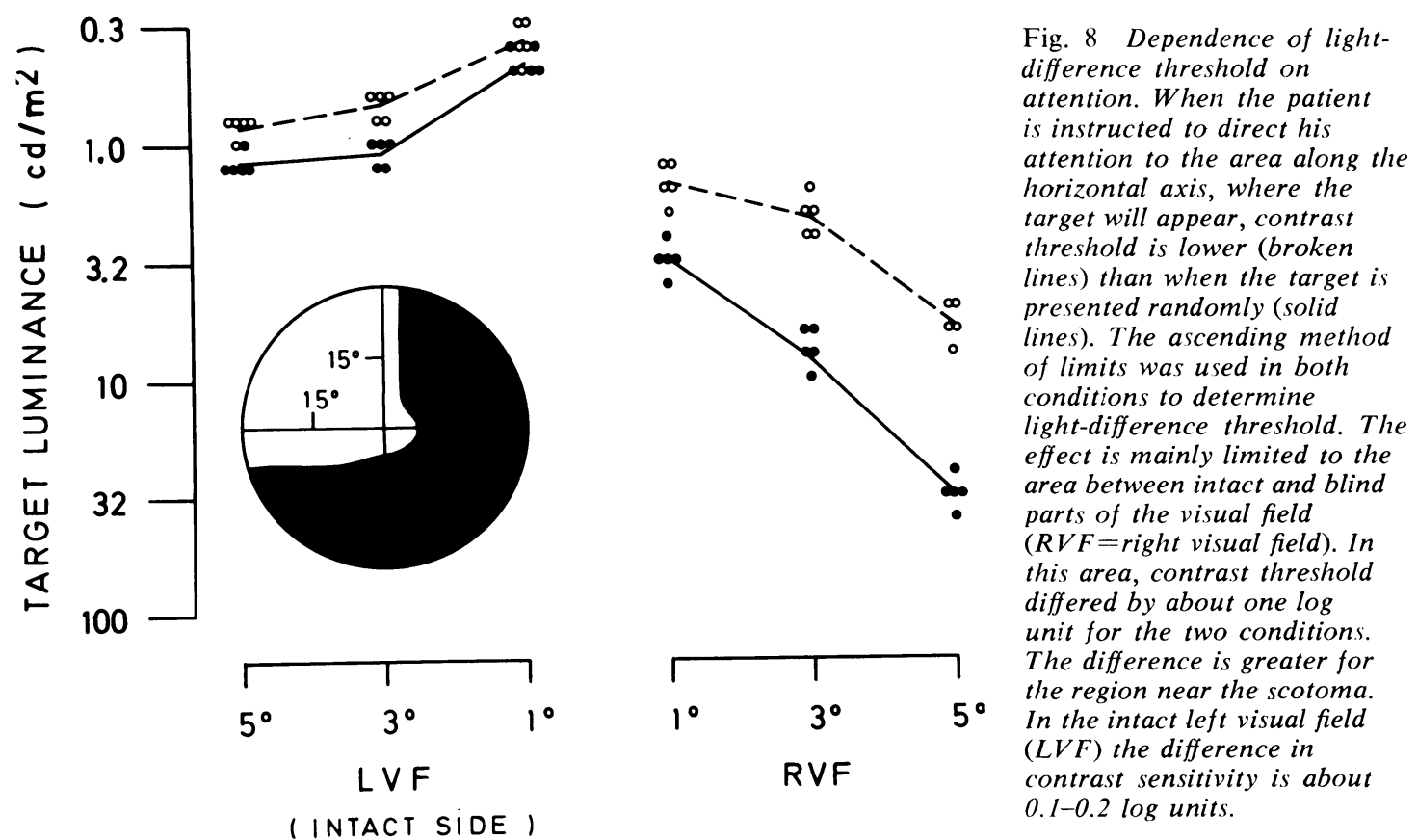

Fig. 8 Dependence of lightucted to direct his horizontal axis, where the target will appear, contrast threshold is lower (broken lines) than when the target $i$. esented randomly (solid conditions to determine light-difference threshold. The effect is mainly limited to the parts of the visual field ( $R V F=$ right visual field). In this area, contrast threshold differed by about one log The difference is greater for the region near the scotoma. $(L V F)$ the difference in 0.1-0.2 log units. 
functional level of the visual cortex does not depend only on the specific visual activity of the neurones but also on other factors such as attention and motivation (Lashley, 1931, 1938). The reduction of these non-visual functions as a secondary effect of the lesion leads probably to a functional reduction of the preserved tissue. Thus loss of visual function may also be caused by reduction of non-visual factors. An improvement of the functional level of the preserved tissue demands an increase of visual attention.

In conclusion, there is evidence now that areas of blindness can be restored in patients with lesions of the central visual pathways. The increase in visual field size as the result of a specific training procedure leads to a remarkable improvement in visual functions such as spatial orientation or reading. The restitution of visual sensory functions may, therefore, be considered as an important part of the rehabilitation of patients with damage to the central nervous system. It remains to be clarified, however, which factors can be used for predicting the amount of the restitution of visual sensory functions and the relevance of this restitution for visual behaviour in these patients.

This work was supported by Deutsche Forschungsgemeinschaft.

\section{References}

Aulhorn, E., and Harms, H. (1972). Visual perimetry. In Handbook of Sensory Physiology, VII/4: Visual Psychophysics, pp. 102-145. Edited by D. Jameson and L. M. Hurvich. Springer: Berlin, Heidelberg, New York.

Bartlett, J. R., and Doty, R. W. (1974). Influence of mesencephalic stimulation on unit activity in striate cortex of squirrel monkeys. Journal of Neurophysiology, 37, 642-652.

Bender, M. B., and Teuber, H. L. (1946). Phenomena of fluctuation, extinction and completion in visual perception. Archives of Neurology and Psychiatry (Chicago), 55, 627-658.

Bergmann, P. S. (1957). Cerebral blindness. Archives of Neurology and Psychiatry (Chicago), 78, 568584.

Cowey, A. (1967). Perimetric study of visual field defects in monkeys after cortical and retinal ablations. Quarterly Journal of Experimental Psychology, 19, 232-245.

Cowey, A., and Weiskrantz, L. (1963). A perimetric study of visual field defects in monkeys. Quarterly Journal of Experimental Psychology, 15, 91-115.

Daniel, P. M., and Whitteridge, D. (1961). The representation of the visual field in the cerebral cortex of monkeys. Journal of Physiology, 159, 203-221.
Farnsworth, D. (1943). The Farnsworth-Munsell 100hue and dichotomous tests for colour vision. Journal of the Optical Society of America, 33, 568-578.

Koerner, F., and Teuber, H.-L. (1973). Visual field defects after missile injuries to the geniculo-striate pathway in man. Experimental Brain Research, 18, 88-113.

Lashley, K. S. (1931). Mass action in cerebral function. Science, 73, 245-254.

Lashley, K. S. (1938). Factors limiting recovery after central nervous lesions. Journal of Nervous and Mental Disease, 88, 733-755.

Lynch, J. C., Mountcastle, V. B., Talbot, W. H., and Yin, T. C. T. (1977). Parietal lobe mechanisms for directed visual attention. Journal of Neurophysiology, 4, 362-389.

Mountcastle, V. B. (1978). Brain mechanisms for directed visual attention. Journal of the Royal Society of Medicine, 71, 14-28.

Pöppel, E., Held, R., and Frost, D. (1973). Residual visual function after brain wounds involving the central visual pathways in man. Nature, 243, 295296.

Pöppel, E., Brinkmann, R., von Cramon, D., and Singer, W. (1978). Association and dissociation of visual functions in a case of bilateral occipital lobe infarction. Archiv für Psychiatrie und Nervenkrankheiten, 225, 1-21.

Poppelreuter, W. (1917). Die psychischen Schädigungen durch Kopfschuss im Kriege 1914/16. Bd. I: Die Störungen der niederen und höheren Sehleistungen durch Verletzungen des Okzipitalhirns, pp. 25-72. Leopold Voss: Leipzig.

Riddoch, G. (1917). Dissociation of visual perception due to occipital injuries, with special reference to appreciation of movement. Brain, 40, 15-57.

Rolls, E. T., and Cowey, A. (1970). Topography of the retina and striate cortex and its relationship to visual acuity in rhesus monkeys and squirrel monkeys. Experimental Brain Research, 10, 298310.

Singer, W. (1973). The effect of mesencephalic reticular stimulation on intracellular potentials of cat lateral geniculate neurons. Brain Research, 61, $35-54$

Singer, W., Tretter, F., and Cynader, M. (1976). The effect of reticular stimulation on spontaneous and evoked activity in the cat visual cortex. Brain $R e$ search, 102, 71-90.

Singer, W., Zihl, J., and Pöppel, E. (1977). Subcortical control of visual thresholds in humans: evidence for modality-specific and retinotopically organized mechanisms of selective attention. Experimental Brain Research, 29, 173-190.

Sloan, L. L. (1971). The Tübinger perimeter of Aulhorn and Harms. Archives of Ophthalmology, 86, 612-622.

Symonds, C., and Mackenzie, J. (1957). Bilateral loss of vision from cerebral infarction. Brain, 80, 415455.

Teuber, H. L. (1974). Recovery of function after lesions of the central nervous system: history and 
prospects. In Functional Recovery after Lesions of the Nervous System. Neurosciences Research Program Bulletin, 12/2, pp. 197-209. Edited by E. Eidelberg and D. G. Stein. MIT Press: Cambridge.

Teuber, H. L. (1975). Recovery of function after brain injury in man. In Outcome of Severe Damage to the Central Nervous System, Ciba Foundation Symposium 34 (new series), pp. 159-186. Elsevier: Amsterdam, Oxford, New York.

Wurtz, R. H., and Goldberg, M. E. (1972). The primate superior colliculus and the shift of visual attention. Investigative Ophthalmology, 11, 441-450.

Zeki, S. M. (1971). Cortical projections from two prestriate areas in the monkey. Brain Research, 34, $19-35$.

Zihl, J., Pöppel, E., and von Cramon, D. (1977a). Diurnal variation in visual field size in patients with postretinal lesions. Experimental Brain Research, 27, 245-249.

Zihl, J., von Cramon, D., Brinkmann, R., and Backmund, H. (1977b). The course and prognosis of scotomas in patients with cerebrovascular disorders. Nervenarzt, 48, 219-224.

Zihl, J., von Cramon, D., and Pöppel, E. (1978). Rehabilitation of sensory functions in patients with post-chiasmatic visual disorders. Nervenarzt, 49, 101-111.

Zihl, J., von Cramon, D., Pöppel, E., and Singer, W. (1979). Interhemispheric modulation of light difference threshold in the periphery of the visual field. In Structure and Function of the Cerebral Commissures. Edited by J. S. Russell. Macmillan: London. In press. 